\title{
Understanding the structure and function of microbial community in acid mine drainage system of Malanjkhand Copper Project, India
}

\author{
Abhishek Gupta \\ Indian Institute of Technology Kharagpur \\ Avishek Dutta \\ Indian Institute of Technology Kharagpur \\ Jayeeta Sarkar \\ Indian Institute of Technology Kharagpur \\ Mruganka Kumar Panigrahi \\ Indian Institute of Technology Kharagpur \\ Pinaki Sar ( $\square$ sarpinaki@yahoo.com ) \\ Indian Institute of Technology Kharagpur https://orcid.org/0000-0001-8538-2527
}

\section{Research}

Keywords: Acid mine drainage, Microbial community composition, Metagenomics, Sulfur- and ironoxidizers, Sulfate- and iron- reducers, Niche-partitioning, Biogeochemistry, Co-occurrence network, Quantitative PCR

Posted Date: January 21st, 2020

DOI: https://doi.org/10.21203/rs.2.19768/v2

License: (9) This work is licensed under a Creative Commons Attribution 4.0 International License. Read Full License 
The authors have withdrawn this preprint from Research Square 